\title{
Pembangunan Perangkat Lunak TrackL Music Sharing Pada Platform Android
}

\author{
Rizky Nugraha ${ }^{1}$, Eko Budi Setiawan ${ }^{2}$ \\ 1,2 Program Studi Teknik Informatika, Universitas Komputer Indonesia \\ Jl. Dipatiukur 112 Bandung \\ saveme.blues@gmail.com ${ }^{1}$, ekobudisetiawan@ymail.com²
}

\begin{abstract}
Abstrak - Mendengarkan musik pada sebuah perangkat mobile smartphone sudah menjadi bagian dalam kehidupan masyarakat seharihari, hal ini semakin diperkuat dengan meningkatnya pendengar musik pada sebuah perangkat mobile. TrackL Music Sharing adalah sebuah perangkat lunak yang berjalan pada perangkat mobile sehingga mudah untuk diakses dan dibawa kemana saja. Perangkat lunak yang dibangun menggunakan dua pemodelan, yaitu pemodelan terstruktur untuk sub sistem web Admin dan pemodelan berbasis objek untuk sub sistem mobile Pengguna. Platform yang digunakan sebagai pilot project untuk sub sistem mobile adalah android, dengan pertimbangan bahwa android saat ini memiliki pengguna paling besar di dunia. Berdasarkan hasil pengujian menggunakan metode pengujian alpha dan beta dapat disimpulkan bahwa perangkat lunak TrackL Music Sharing telah membantu pendengar musik untuk memperoleh informasi Trending Music, bergabung dalam sebuah Music Circle, dan saling merekomendasikan musik pada sebuah playlist yang berdasarkan Music Circle.
\end{abstract}

Kata Kunci - Music Sharing, Circle, Playlist, Genre, Perangkat Lunak Mobile, Android.

\section{PENDAHULUAN}

Mendengarkan musik pada sebuah
perangkat mobile smartphone sudah menjadi
bagian dalam kehidupan masyarakat sehari-hari,
hal ini semakin diperkuat dengan meningkatnya
pendengar musik pada sebuah perangkat mobile
smartphone yang terjadi pada setiap tahunnya.
Sebuah survei dari lembaga eMarketer pada tahun
2013 menunjukkan bahwa orang Amerika lebih
memilih mendengarkannya dari perangkat
mobile daripada melalui perangkat lain. Sebanyak
147 juta orang Amerika diketahui mendengarkan
radio online setidaknya sekali dalam sebulan,
sementara 70 juta orang memilih mendengarkan
musik di perangkat mobile-nya. Hal ini meningkat

cukup tajam dibanding tahun sebelumnya, jumlah pendengar musik dari smartphone hanya 61 juta orang, sedangkan pendengar radio melalui smartphone mencapai 133 juta orang [1] .

Mendengarkan musik tentunya tidak terlepas dari beberapa masalah, berdasarkan survei dari kuesioner yang dilakukan kepada para responden pendengar musik indie, bahwa terdapat $68 \%$ dari responden mengatakan sulitnya dalam pencarian lagu untuk sebuah playlist yang sesuai dengan trending dan genre musik, $79 \%$ responden mengatakan adanya penyesuaian dalam mendengarkan musik sesuai dengan genre musik dan $84 \%$ dari responden mengatakan adanya keinginan untuk berbagi dan merekomendasikan musik berdasarkan genre kepada beberapa teman mereka yang memiliki kesamaan terhadap genre musik tertentu, yang bertujuan untuk dapat saling berbagi informasi musik sesuai dengan genre yang mereka suka. Namun terkadang mereka sulit untuk dapat bertemu dengan orang-orang yang memiliki ketertarikan yang sama dari genre musiknya.

Meskipun terdapat beberapa aplikasi yang ditujukan khusus untuk pendengar musik, contohnya seperti SoundCloud dan LastFm, akan tetapi belum ada aplikasi music sharing yang selain dari mendengarkan musik secara streaming, namun dapat membuat sebuah Circle seperti misalnya sebuah Circle musik Indie Folk dimana didalamnya terdapat orang-orang yang menyukai musik bergenre Folk, mereka dapat membuat sebuah playlist mereka dan meng-invite temantemannya, mereka dapat memposting beberapa musik yang didengarkan pada Circle Indie Folk tentunya sehingga akan adanya rekomendasi terhadap musik bergenre Folk yang sedang trend maupun enak untuk didengar para penikmat musik Indie Folk. Mereka juga bisa saling berbagi informasi tentang musik sehingga lebih terfokus terhadap suatu genre musik dalam satu Circle yang sesuai.

Oleh karena itu, berdasarkan uraian di atas maka akan dibangun sebuah perangkat lunak dengan tujuan dapat membantu para pendengar musik untuk berbagi melalui sebuah aplikasi music sharing yang dikhususkan untuk pengguna smartphone. Adapun platform yang digunakan sebagai pilot project perangkat lunak ini adalah 
android dengan pertimbangan bahwa saat ini android memiliki market share sebesar $70 \%$ dari seluruh smartphone yang diaktifkan [2].

\section{LANDASAN TEORI}

A. Musik

Menurut M.Soeharto dalam buku "Kamus Musik" dijelaskan bahwa musik adalah pengungkapan melalui gagasan melalui bunyi, yang unsur dasarnya berupa melodi, irama, dan harmoni dengan unsur pendukung berupa gagasan, sifat dan warna bunyi [4]. Musik merupakan seni yang timbul dari perasaan atau pikiran manusia sebagai pengungkapan ekspresi diri, yang diolah dalam suatu nada-nada atau suara-suara yang harmonis. Jika musik diartikan sebagai ungkapan sederhana dari suasana hati jiwa atau respon harafiah terhadap peristiwa dari diri pribadi komponis, diperlukan informasi ataupun referensi yang cukup agar kita dapat menarik hubungan langsung antara kehidupan dengan karyanya [4].

\section{B. Genre Music}

Genre musik sulit untuk digambarkan karena tidak ada kesepakatan lengkap tentang definisnya. "Genre muncul sebagai istilah dan kata benda yang mendefinisikan kekambuhan dan kesamaan bahwa anggota dari masyarakat membuat berhubungan dengan mengidentifikasi acara musik" [5]. Genre Musik merupakan pengelompokan musik sesuai dengan kemiripannya satu sama lain. Genre Musik dapat dikelompokan sesuai dengan kriteria yang dapat didefinisikan oleh teknik musik, gaya, konteks, dan tema musik. Berdasarkan hasil dari penjabaran jenis musik, terdapat dua istilah yaitu Sidestream Music dan Mainstream Music, terlihat seberapa besar jenis musik tersebut dapat diterima dan dinikmati oleh masyarakat secara universal yang kemudian kaitannya menjadi sasaran industri.

\section{Android}

Android adalah sistem operasi bersifat Open Source berbasis Linux dirancang untuk perangkat seluler layar sentuh seperti telepon pintar dan komputer tablet. Android awalnya dikembangkan oleh Android, Inc., dengan dukungan finansial dari Google, yang kemudian membelinya pada tahun 2005. Sistem operasi ini dirilis secara resmi pada tahun 2007, bersamaan dengan didirikannya Open Handset Alliance, konsorsium dari perusahaanperusahaan perangkat keras, perangkat lunak, dan telekomunikasi yang bertujuan untuk memajukan standar terbuka perangkat seluler. Ponsel Android pertama mulai dijual pada bulan Oktober 2008
[10]. Android memiliki OS yang sangat baik, cepat dan kuat serta memiliki antarmuka pengguna intuitif yang dikemas dengan pilihan dan fleksibilitas. Android SDK (Software Development Kit) menyediakan tools dan API yang diperlukan untuk mengembangkan aplikasi pada platform android dengan menggunakan bahasa pemrograman Java.

\section{Pengujian Black Box}

Pengujian blackbox fokus pada keperluan penelusuran kesalahan fungsional dari software. Ujicoba blackbox berusaha untuk menemukan kesalahan dalam beberapa kategori, diantaranya :

1. Fungsi-fungsi yang salah atau hilang

2. Kesalahan interface

3. Kesalahan dalam struktur data atau akses database eksternal

4. Kesalahan performa

5. Kesalahan inisialisasi dan terminasi

Teknik pengujian black box terdiri dari 10 jenis diantaranya Equivalence Partitioning, Boundary Value Analysis/Limit Testing, Comparison Testing, Sample Testing, Robustness Testing, Behavior Testing, Requirement Testing, Performance Testing, Endurance Testing, CauseEffect Relationship Testing. Salah satunya yang akan dibahas adalah Equivalence partitioning.

Equivalence partioning merupakan metode ujicoba blackbox yang membagi domain input dari program menjadi beberapa kelas data dari kasus ujicoba yang dihasilkan. Kasus uji penanganan single yang ideal menemukan sejumlah kesalahan (misalnya : kesalahan pemrosesan dari seluruh data karakter) yang merupakan syarat lain dari suatu kasus yang dieksekusi sebelum kesalahan umum diamati.

\section{HASIL DAN PEMBAHASAN}

\section{A. Analisis dan Perancangan Sistem}

Pada proses analisis dan perancangan sistem, akan dibahas menenai analisis masalah, analisis data, analisis kebutuhan fungsional subsistem website, analisis kebutuhan fungsionalitas subsistem android.

\section{A.1 Analisis Masalah}

Dalam penggunaan aplikasi pemutar musik seperti SoundCloud dan LastFm untuk mendengarkan musik secara streaming online dan rekomendasi musik, masih terdapat beberapa fitur yang belum mendukung kebutuhan pendengar musik untuk berbagi musiknya. Akan tetapi dalam berbagi musik tidaklah mudah karena terdapat 
beberapa masalah. Masalah-masalah tersebut diantaranya adalah:

1. Pendengar musik masih merasa sulit untuk mengetahui trend musik yang sesuai dengan genre musik yang ada.

2. Pendengar musik merasa kesulitan untuk dapat bergabung dengan orang-orang dalam sebuah circle dan berdasarkan kesukaan genre musiknya.

Pendengar musik merasa kesulitan untuk dapat saling berbagi dan merekomendasikan musik pada sebuah playlist.

\section{A.2 Analisis Data}

Berikut akan disampaikan mengenai Entity Relationship Diagram (ERD) dari perangkat lunak yang dibangun. ERD tersebut dapat dilihat pada gambar 1. Sedangkan untuk skema relasi dapat dilihat pada gambar 2 .

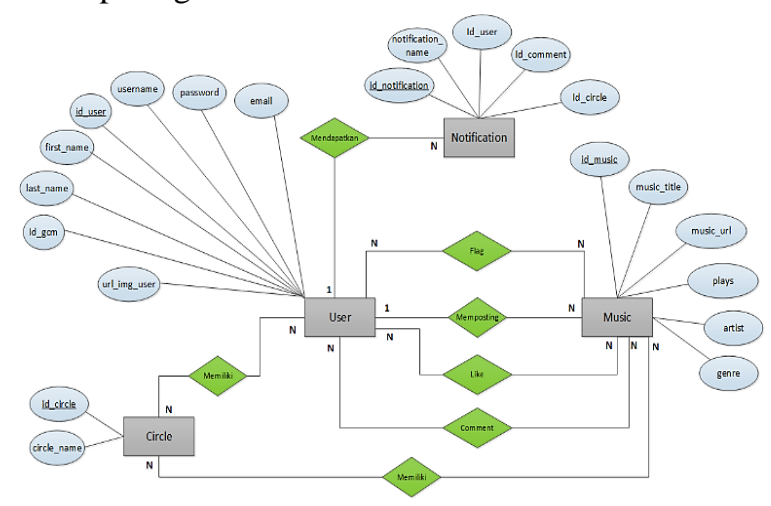

Gambar 1 Entity Relationship Diagram Perangkat Lunak

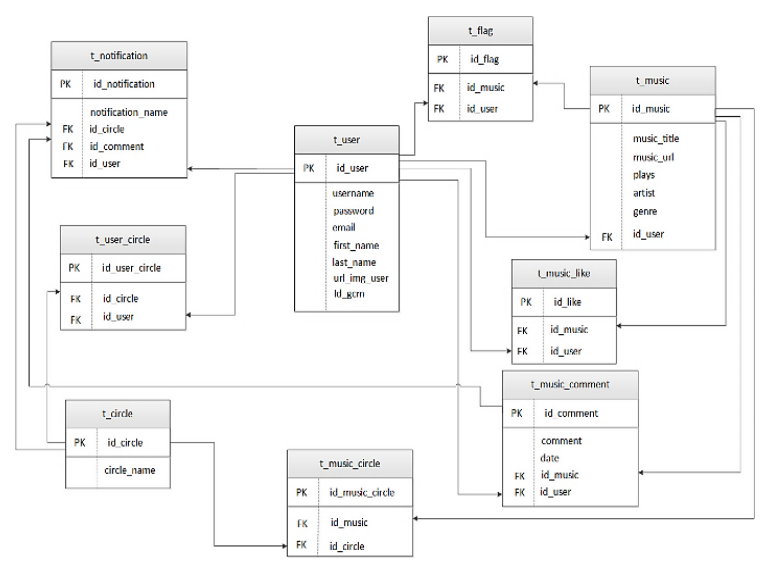

\section{Gambar 2 Skema Relasi Database Perangkat Lunak}

\section{A.3 Analisis Kebutuhan Fungsionalitas Subsistem Web}

Analisis kebutuhan fungsional yang dibahas berupa digram konteks dan Data Flow Diagram (DFD) Level 1 Untuk diagram konteks perangkat lunak dapat dilhat pada gambar 3, sedangkan DFD Level 1 dapat dilihat pada gambar 4 berikut.

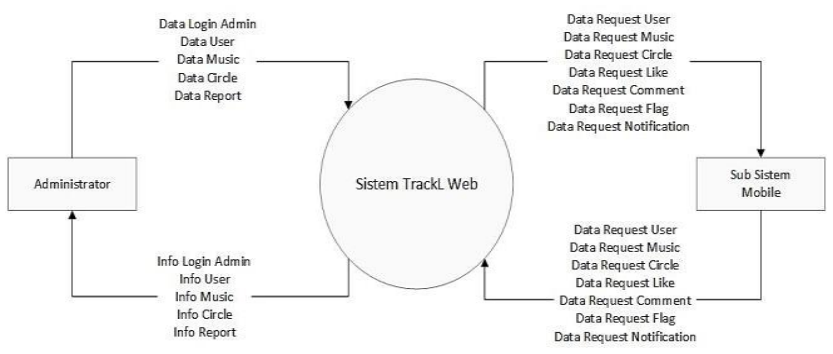

Gambar 3 Diagram Konteks Perangkat Lunak

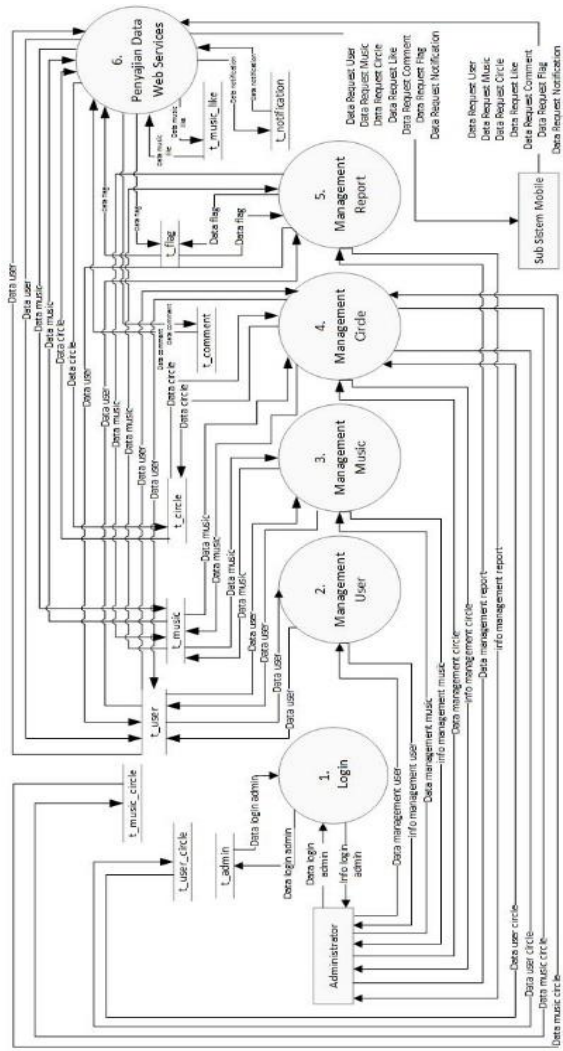

Gambar 4 DFD Level 1 Perangkat Lunak

\section{A.4 Analisis Kebutuhan Fungsionalitas Subsistem Android \\ Berikut merupakan usecase dari perangkat lunak subsistem Android yang dibangun.}




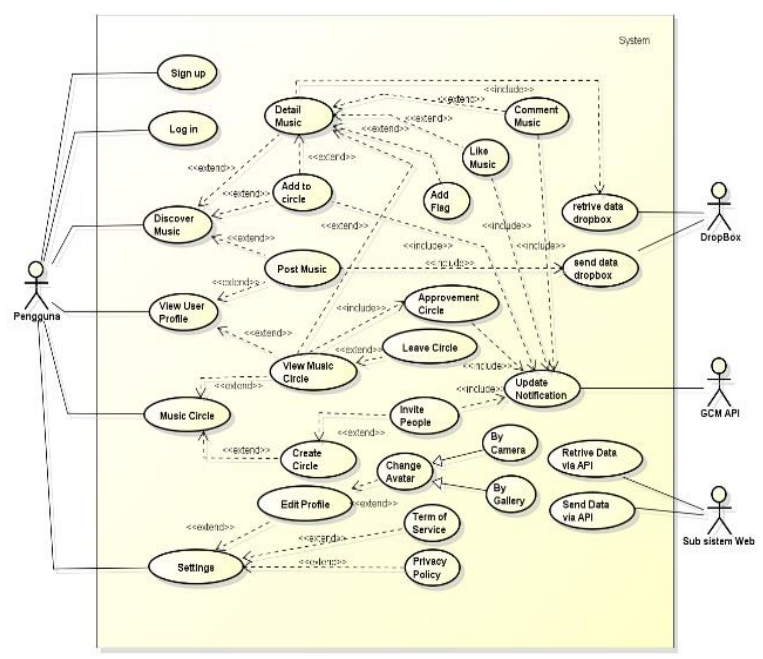

Gambar 5 Usecase Perangkat Lunak

\section{A.5 Analisis Arsitektur Sistem Web}

Platform web adalah salah satu subsistem yang dipilih untuk pembangunan dari perangkat lunak ini. Pengguna perangkat lunak platform ini terbagi menjadi dua yaitu Administrator dan pengguna. Administrator bertugas untuk mengolah data konten pengguna. Berikut adalah Error! Reference source not found.. Gambar ini menggambarkan secara keseluruhan arsitektur sistem pada platform web.

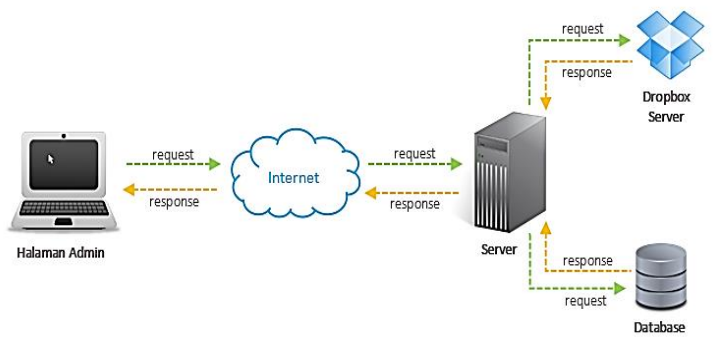

\section{Gambar 6 Arsitektur Perangkat Lunak Pada Platform Web}

Berikut adalah deskripsi dari Error! Reference source not found. :

1. Sub sistem web Admin dan pengguna melakukan request permintaan data ke server melalui jaringan internet.

2. Server menerima request permintaan data dan mengambil data sesuai permintaan dari database. Jika data yang diminta ada di server dropbox maka server membuat request yang dikirimkan ke server dropbox.

3. Server dropbox memberikan respon data yang diminta server dan mengirimkan data tersebut kembali ke server.

4. Server mengirimkan data yang diminta melalui jaringan internet ke komputer Admin dan pengguna.

\section{A.6 Analisis Arsitektur Sistem Mobile}

Platform mobile adalah salah satu subsistem yang dipilih untuk pembangunan dari perangkat lunak ini. Arsitektur perangkat lunak pada platform mobile mengambarkan bagaimana perangkat lunak saling berinteraksi seperti diilustrasikan pada Error! Reference source not found. Gambar tersebut menggambarkan keseluruhan arsitektur sistem pada platform mobile.

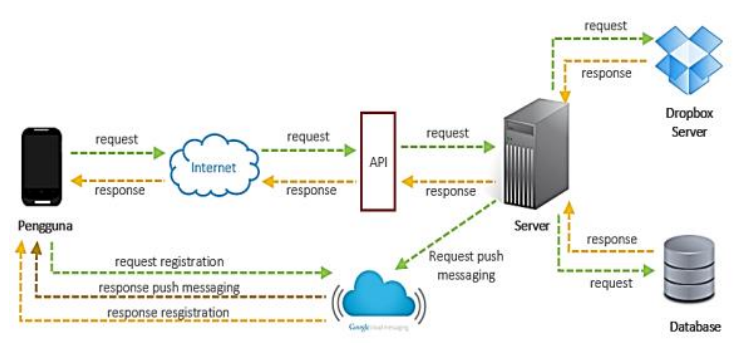

Gambar 7 Arsitektur Perangkat Lunak Pada Platform Mobile

Berikut adalah deskripsi dari Error!

Reference source not found.:

1. Perangkat mobile pengguna melakukan request data ke server melalui API

2. Server menerima request data dari server dan menentukan jenis request yang diminta

3. Jika server menerima permintaan data file music maka permintaan data akan diteruskan ke server dropbox.

4. Jika server menerima permintaan data text maka server akan langsung mengambil data yang ada di database.

5. Setelah server menerima data yang diminta data tersebut akan dikembalikan dalam bentuk JSON untuk diproses perangkat mobile pengguna.

6. Ketika perangkat mobile melakukan registrasi atau login, disitulah akan dilakukan request untuk meregisterkan perangkat mobile agar mendapatkan id Google Cloud Messaging (GCM).

7. Jika pengguna melakukan request untuk mengirim notifikasi maka server akan melakukan request ke GCM, selanjutnya GCM akan merespon dan melakukan push messaging ke perangkat mobile.

\section{A.7 Analisis Arsitektur Sistem Keseluruhan}

Setelah mengetahui arsitektur sistem platform web dan mobile, pada gambar 8 ditampilkan analisis arsitektur sistem secara kesluruhan. 


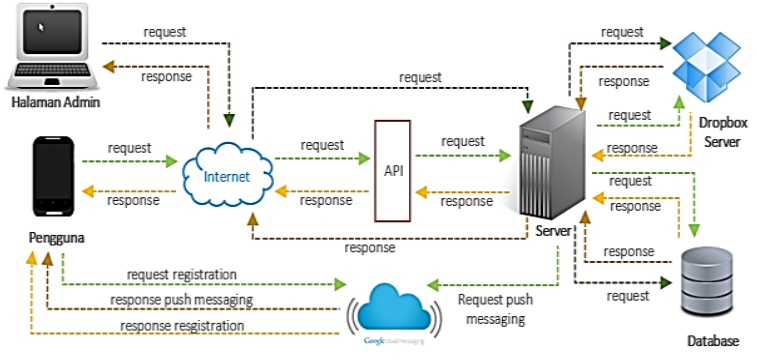

\section{Gambar 8 Arsitektur Perangkat Lunak Keseluruhan}

\section{B. Implementasi dan Pengujian Sistem}

Pada proses implementasi dan pengujian sistem, akan dibahas mengenai bahasan lingkungan implementasi yang terdiri dari perangkat lunak pembangun, spesifikasi hardware untuk mengakses sistem, serta spesifikasi kebutuhan sistem. Pada tahapan pengujian sistem, yang akan dibahas yaitu implementasi antarmuka dan hasil pengujain sistem.

\section{B.1 Lingkungan Implementasi}

Lingkungan implementasi merupakan spesifikasi hardware, software dan server dimana sistem ini akan dipasang dan diakses.

Tabel 1. Lingkungan Hardware Pembangun Perangkat Lunak

\begin{tabular}{|c|l|l|}
\hline No & \multicolumn{1}{|c|}{ Item } & \multicolumn{1}{|c|}{ Spesifikasi } \\
\hline 1 & Processor & $\begin{array}{l}\text { Intel(R) Core i5 2430M } \\
\text { CPU @ 2.40 Ghz } \\
\text { (4CPUs) 2.4GHz }\end{array}$ \\
\hline 2 & Harddisk & $750 \mathrm{~GB}$ \\
\hline 3 & Memory & $4 \mathrm{~GB}$ \\
\hline 4 & VGA & $2 \mathrm{~GB}$ \\
\hline 5 & Monitor & 14 inch \\
\hline 6 & Mouse & Optical Logitech \\
\hline 7 & Keyboard & QWERTY Creative \\
\hline 8 & Speaker & Earpiece, Loudspeaker \\
\hline 9 & USB port & 3 buah \\
\hline 10 & Koneksi Internet & Ada \\
\hline 11 & Android & $\begin{array}{l}\text { Android 4.3 inch dan 5 } \\
\text { inch }\end{array}$ \\
\hline
\end{tabular}

Spesifikasi hardware untuk mengakses sistem dapat dilihat pada tabel 2.
Tabel 2. Lingkungan Hardware Pembangun Perangkat Lunak

\begin{tabular}{|c|l|l|}
\hline No & \multicolumn{1}{|c|}{ Website } & \multicolumn{1}{c|}{ Android } \\
\hline 1 & $\begin{array}{l}\text { Processor @ 1.6 } \\
\text { Ghz }\end{array}$ & $\begin{array}{l}\text { 1. Processor @800 } \\
\text { Mhz }\end{array}$ \\
\hline 2 & Harddisk 80 GB & 2. SD Card 1 GB \\
\hline 3 & Memory 1 GB & 3. TFT LCD \\
\hline 4 & VGA 128 MB & 4. Memory 512 MB \\
\hline 5 & Monitor 14 inch & 5. Speaker \\
\hline 6 & $\begin{array}{l}\text { Mouse dan } \\
\text { Keyboard 6. Koneksi Internet }\end{array}$ & $\begin{array}{l}\text { USB port } \\
\text { minimal 2 }\end{array}$ \\
\hline 8 & Koneksi Internet \\
\hline
\end{tabular}

Berikut adalah spesifikasi kebutuhan software yang digunakan dalam pembangunan perangkat lunak ini adalah:

1. Sistem Operasi Windows 8.164 bit.

2. Bahasa pemrograman PHP \& Java.

3. DBMS : MySQL 5.5.40

4. Web Browser : Google Chrome 39.0.2171.95

5. Code Editor menggunakan Sublime text 3.

6. Web Server : XAMPP.

7. Aplikasi android dibangun menggunakan SDK android yang terpasang pada IDE Eclipse Version Luna 4.4.1 Service Release 164 bit.

8. Pertukaran data yang dilakukan menggunakan JSON.

Berikut adalah spesifikasi software untuk mengakses sistem:

Tabel 3. Lingkungan Software

\begin{tabular}{|c|c|}
\hline Sub Sistem web & Sub Sistem Mobile \\
\hline $\begin{array}{ll}\text { Sistem } & \text { Operasi } \\
\text { Windows } 8 & \end{array}$ & $\begin{array}{l}\text { Sistem } \\
\text { Android } 4.0 \text { Ice } \\
\text { Cream Sandwich }\end{array}$ \\
\hline $\begin{array}{l}\text { Web Browser Mozilla } \\
\text { Firefox 20.0, Google } \\
\text { Chrome } 39.0 .2171 .95\end{array}$ & \\
\hline
\end{tabular}

Untuk kebutuhan server, spesifikasi yang dibutuhkan dari sisi server yang digunakan untuk melayani request sistem dapat dlihat pada tabel 4 . 
Tabel 4 Kebutuhan Spesifikasi Server

\begin{tabular}{|l|}
\hline \multicolumn{1}{|c|}{ Sub Sistem Web } \\
\hline Web Space 500 MB \\
\hline Bandwidth 50 GB Bulan \\
\hline MySQL Database (5.5.40 -cll) \\
\hline PHP (5.4.36) \\
\hline CPanel 11.46.2 \\
\hline Apache 2.2.29 \\
\hline
\end{tabular}

\section{B.2 Implementasi Antarmuka Sub Sistem Web} Berikut adalah implementasi antarmuka dari subsistem web yang dapat dilihat pada gambar 9 dan gambar 10.

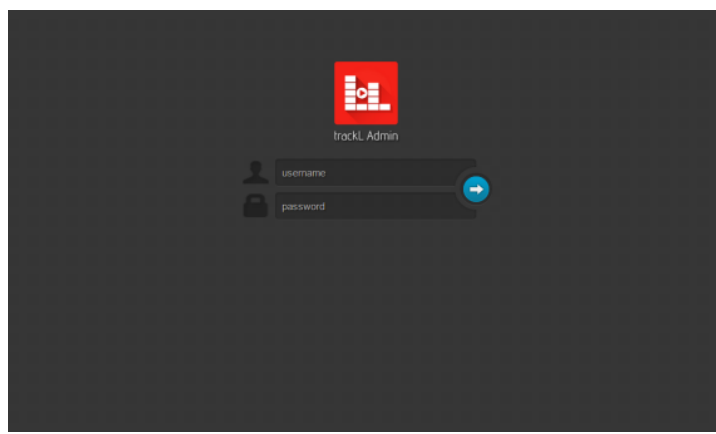

Gambar 9 Tampilan Antarmuka Login Web

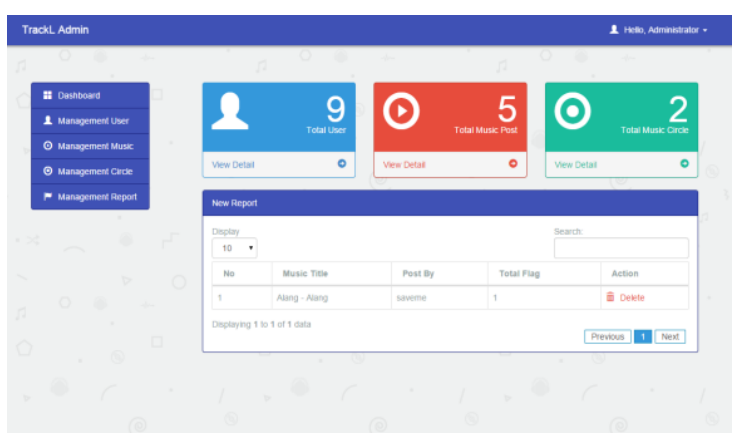

\section{Gambar 10 Implementasi Antarmuka Dashboard Web}

B.3 Implementasi Antarmuka Sub Sistem Mobile Android

Berikut adalah implementasi antarmuka dari sistem platfom mobile android yang dapat dilihat pada gambar 11
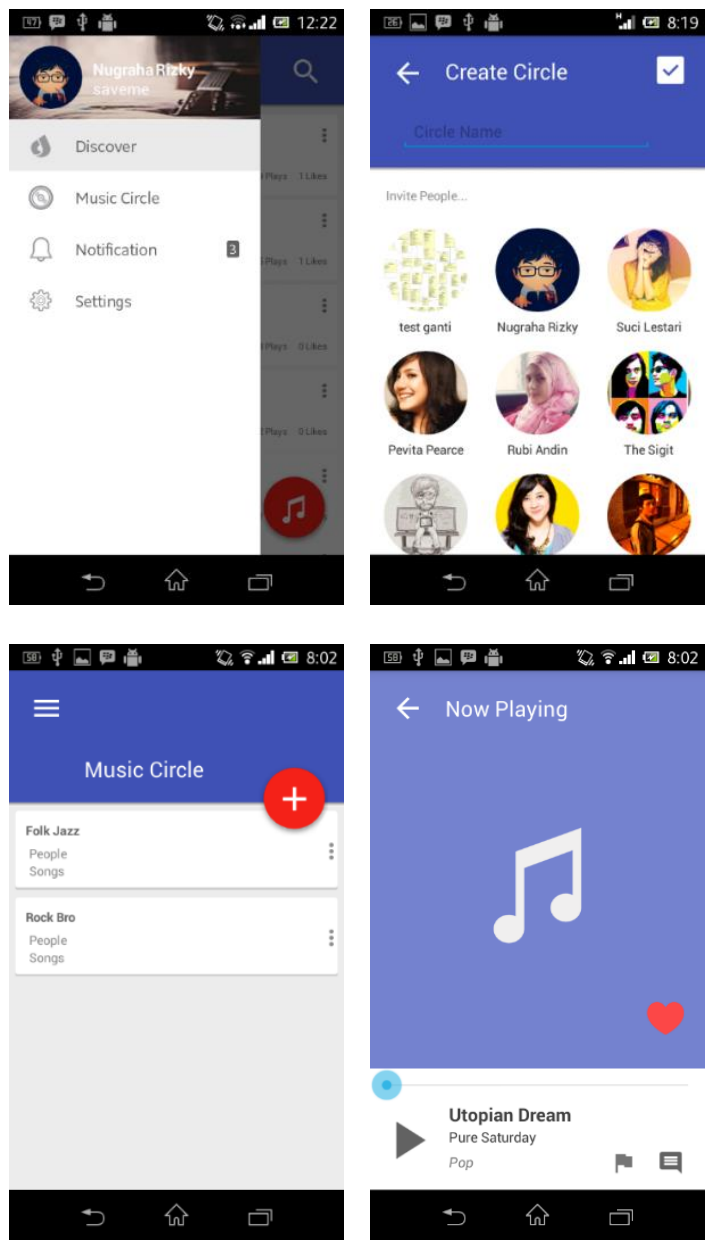

Gambar 11 Implementasi Antarmuka Platform Mobile Android

B.4 Implementasi Antarmuka Sub Sistem Mobile Android

Berikut adalah hasil pengujian dari pembangunan perangkat lunak TrackL Music Sharing yang telah dilakukan

1. Evaluasi pengujian fungsional

Berdasarkan hasil pengujian fungsional yang dilakukan maka dapat disimpulkan bahwa sub sistem web dan mobile yang dibangun sudah berjalan sesuai dengan yang diharapkan baik itu dari segi validasi maupun proses penanganan kesalahan.

2. Evaluasi pengujian Kuesioner

Berdasarkan hasil pengujian kuesioner yang telah dilakukan terjadap 27 responden, didapat kesimpulan hasil pengujian kuesioner seperti pada tabel 5 berikut : 
Tabel 5 Hasil Pengujian Kuesioner

\begin{tabular}{|l|l|l|}
\hline No & \multicolumn{1}{|c|}{ Tujuan } & \multicolumn{1}{|c|}{$\begin{array}{c}\text { Evaluasi } \\
\text { Hasil }\end{array}$} \\
\hline 1 & $\begin{array}{l}\text { Membantu pendengar } \\
\text { musik untuk } \\
\text { mendapatkan informasi } \\
\text { trending music }\end{array}$ & Membantu \\
\hline 2 & $\begin{array}{l}\text { Membantu pendengar } \\
\text { musik untuk dapat } \\
\text { bergabung dalam } \\
\text { sebuah circle } \\
\text { berdasarkan genre } \\
\text { music }\end{array}$ & Membantu \\
\hline 3 & $\begin{array}{l}\text { Membantu pendengar } \\
\text { musik untuk dapat dapat } \\
\text { saling berbagi dan } \\
\text { merekomendasikan } \\
\text { musik pada sebuah } \\
\text { playlist yang } \\
\text { berdasarkan music } \\
\text { circle }\end{array}$ & Membantu \\
\hline 4 & $\begin{array}{l}\text { Membangun perangkat } \\
\text { lunak yang mudah dan } \\
\text { benar dari segi UX dan } \\
\text { UI }\end{array}$ & Membantu \\
\hline
\end{tabular}

\section{KESIMPULAN DAN SARAN}

Adapun kesimpulan dan saran yang didapatkan dari hasil penelitian ini yaitu :

\section{A. Kesimpulan}

Berdasarkan hasil pengujian perangkat lunak music sharing pada platform android maka diperoleh kesimpulan sebagai berikut:

1. Perangkat lunak TrackL Music Sharing pada platform android sudah membantu pengguna untuk memperoleh informasi trending music.

2. Perangkat lunak TrackL Music Sharing pada platform android sudah membantu pengguna untuk dapat bergabung di dalam sebuah music circle dengan orang-orang yang memiliki kesukaan yang sama terhadap genre musiknya.

3. Perangkat lunak TrackL Music Sharing pada platform android sudah membantu para pendengar musik untuk saling merekomendasikan musiknya pada sebuah playlist yang berdasarkan music circle.

\section{B. Saran}

Adapun saran terhadap pengembangan aplikasi ini adalah Perangkat lunak TrackL Music Sharing yang dibangun merupakan produk yang berfokus kepada domain music sharing, Oleh karena itu ada beberapa saran yang dapat digunakan sebagai paduan pengembangan perangkat lunak ke arah yang lebih baik guna mendukung pertumbuhan pengguna dan konten pada perangkat lunak ini. Adapun saran-saran terhadap pengembangan perangkat lunak TrackL Music Sharing ini adalah sebagai berikut:

1. Meningkatkan jumlah konten musik agar pengguna lebih memiliki banyak rekomendasi dalam berbagi musiknya.

2. Mengembangkan perangkat lunak dari segi performansi dan pengalaman pengguna yang lebih baik.

3. Mengembangkan platform yang dapat didukung oleh semua perangkat lunak mobile mengingat saat ini hanya mendukung pada platform android.

\section{REFERENSI}

[1] A. W. Savitri, "Survei: Mendengarkan Musik \& Radio di Smartphone Terus Meningkat,"[Online].Available:http://techn o.okezone.com/read/2013/08/15/57/849845 /survei-mendengarkan-musik-radio-dismartphone-terus-meningkat.

[2] I. Lunden, "Kantar: Android Accounted For $70 \%$ Of Smartphone Sales In Q4, But Samsung Is Now "Under Real Pressure," January 2014. [Online]. Available: http://techcrunch.com/2014/01/26/kantarandroid-sales-in-q4-grew-in-all-bigmarkets-but-leader-samsung-now-underreal-pressure.

[3] I. Sommerville, "Software Engineering, Eight Edition ed," Addison Wesley, 2007.

[4] M. Soeharto, "Kamus Musik Indonesia," Jakarta, Gramedia, 1978.

[5] R. B. P. Annesi, "Audio Feature Engineering for Automatic Music Genre Classification," Paris, Pittburgh, 2007.

[6] I. Rez, Music Records Indie Label, Bandung: Dar! Mizan, 2008.

[7] I. Nuraida, "Manajemen Administrasi Perkantoran," Yogyakarta, Kanisius, 2008.

[8] K. Abdul, "Pengenalan Sistem Informasi," Yogyakarta, Andi, 2002.

[9] Indrajani, "Analisis dan Perancangan Sistem Informasi Card Management," Berbagai Makalah Sistem Informasi dalam KNSI 2009, vol. Indonesia: Informatika, p. $15,2009$. 
[10] R. Schwarz, P. Dutson, J. Stelee and N. To, The Android Developer's Cookbook, 2nd ed., New York, United States: AddisonWesley, 2013.

[11] I. Google, "Introduction to Android," [Online]. Available: http://developer.android.com/guide/index.h tml.

[12] I. A. Bureau, "User Generated Content, Social Media and Advertising," User Generated Content, Social Media and Advertising, pp. 1-5, 2008.

[13] J. Simarmata, Rekayasa Web, Yogyakarta: ANDI, 2010.

[14] json. org, “json org," 2014. [Online]. Available: http://json.org/json-id.

[15] H. J. R. G. Shelly, Systems Analysis and Design, Boston: Course technology cengange learning, 2010.

[16] H. Divayana, Konsep OOAD, Jakarta: Eresha, 2010.

[17] J. Hermawan, Analisa Desain \& Pemrograman Berorientasi Objek dengan UML dan Visual Basic.NET, Yogyakarta: Andi, 2010.

[18] K. H. d. R. Miles, Learning UML 2.0, United States of America: O'Reilly, 2006.

[19] S. M. P. P. H. E. T. Ruseffendi, Dasar-dasar penelitian \& Bidang non eksakta lainnya, Bandung: PT Tarsito Bandung, 2005. 